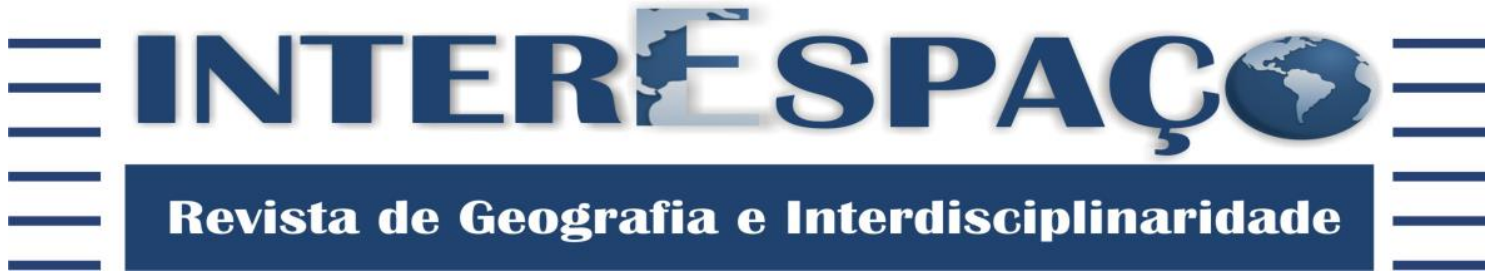

\section{GESTÃO DO TERRITÓRIO: análise econômica da mineração nos municípios da Amazônia Oriental paraense (2010 a 2017)}

TERRITORIAL MANAGEMENT: economical analysis in counties with mining in the Eastern Amazon paraense (2010 to 2017)

\section{GESTIÓN DEL TERRITORIO: análisis económico de la minería en los municipios de la Amazonia Oriental Pará (2010 a 2017)}

\author{
Gláucia Rodrigues Nascimento Medeiros \\ Doutoranda em Geografia pela Universidade Federal do Pará - UFPA. \\ glaurn@uol.com.br

\section{Marcus Vinicius Batella Medeiros} \\ Mestre em Engenharia de Defesa pelo Instituto Militar de Engenharia - IME. \\ marcus.medeiros@uol.com.br

\section{Luana Faria Medeiros} \\ Mestranda em Geografia pela Universidade Federal do Pará - UFPA. \\ luacfaria@yahoo.com.br \\ Recebido para avaliação em 31/08/2017; Aceito para publicação em 07/11/2017.
}

\section{RESUMO}

A Amazônia Oriental ao qual o Pará está inserido apresenta abundantes riquezas energéticas, possuindo uma elevada arrecadação de recursos advindos das atividades de exploração econômica. Tais recursos se traduzem em impostos, taxas e compensações, movimentando o PIB do Estado do Pará e dos Municípios de Parauapebas e Canaã dos Carajás, colocando o estado e os municípios como os principais vetores econômicos, devido as exorbitantes cifras de milhões de reais arrecadadas, sendo responsável pela influência direta do Produto Interno Bruto Nacional (PIB), dos Estados e dos Municípios que recebem tais receitas. Ao se pensar em uma efetiva Gestão do Território, se faz necessário avaliar o montante arrecadado anualmente, para posteriormente mensurar se as aplicações estão agregando valor e sendo revertidos na melhoria da qualidade de vida local, em investimentos em infraestrutura, na qualidade ambiental na saúde e educação da população dos municípios impactados. Neste primeiro momento é necessário incrementar a pesquisa da região, buscando servir de aporte para os atores locais e posteriormente, realizar uma avaliação de desempenho contínua, buscando mais efetividade e objetivação no desenvolvimento dos territórios impactados.

Palavras-chave: Amazônia Oriental; Mineração; Pará; Território.

\section{ABSTRACT}

The Eastern Amazon, where Pará is inserted, presents abundant energetic wealth, possessing a high ammount of resources derived from the activities of economic exploration. These resources are converteded into taxes, fees and compensation, moving the GDP of the state of Para and the municipalities of Parauapebas and Canaã dos Carajás, placing the state and municipalities as the main economic vectors, due to the exorbitant figures of millions of reais collected, being responsible for the direct influence of the National Gross National Product (GDP), of the States and Municipalities that receive such revenues. When thinking about an effective Land Management, 
Dossiê: Impactos e repercussões territoriais de empreendimentos na Pan-Amazônia | Gestão do território: análise econômica da mineração nos municípios da Amazônia Oriental paraense (2010 a 2017)|

| Gláucia Rodrigues Nascimento Medeiros | Marcus Vinicius Batella Medeiros |Luana Faria Medeiros | it is necessary to evaluate the amount of tributes collected annually, to later measure if the applications are adding value and being reverted in the improvement of local quality of life, investments in infrastructure, environmental quality in health and education of the population of impacted municipalities. In this first moment it is necessary to increase the research into the region, seeking to contribute to the local actors and later, to carry out an evaluation of continuous performance, seeking more effectiveness and objectivation in the development of the impacted territories.

Keywords: Eastern Amazon; Mining; Pará; Territory.

\section{RESUMEN}

La Amazonia Oriental al cual el Pará está inserto presenta abundantes riquezas energética, poseyendo una elevada recaudación de recursos provenientes de las actividades de explotación económica. Tales recursos se traducen en impuestos, tasas y compensaciones, moviendo el PIB del Estado de Pará y de los Municipios de Parauapebas y Canaã dos Carajás, colocando el estado y los municipios como los principales vectores económicos, debido a las exorbitantes cifras de millones de reales recaudados, Siendo responsable de la influencia directa del Producto Interno Bruto Nacional (PIB), de los Estados y de los Municipios que reciben dichos ingresos. Al pensar en una efectiva Gestión del Territorio, se hace necesario evaluar el monto recaudado anualmente, para posteriormente medir si las aplicaciones están agregando valor y siendo revertido en la mejora de la calidad de vida local, en inversiones en infraestructura, en la calidad ambiental en la salud y Educación de la población de los municipios afectados. En este primer momento es necesario incrementar la investigación de la región, buscando servir de aporte para los actores locales y posteriormente, realizar una evaluación de desempeño continua, buscando más efectividad y objetivación en el desarrollo de los territorios impactados.

Palabras clave: Amazonia Oriental; Minería; Pará; Territorio.

\section{INTRODUÇÃO}

Devido aos grandes impactos negativos econômicos e ambientais causados no território advindos dos grandes projetos na Amazônia, onde suas benesses não se fixam ou não são direcionadas para o bem-estar local, surgem discordâncias, dúvidas e anseios acerca de qual seria a relevância em se criar, manter ou ampliar um grande projeto estratégico nos territórios paraenses, em especial, nos municípios que possuem algum vínculo com a mineração.

Não se pode desconsiderar a importância que a mineração possui para o PIB (Produto Interno Bruto) federal, estadual e municipal, pois tal atividade é uma das responsáveis pelo aumento dos recursos financeiros dos mais de 50 municípios paraenses que surgiram, subexiste ou incrementam suas receitas através das taxas, impostos ou compensações advindas da mineração. Um dos principais recursos advindos da mineração é denominado CFEM (Compensação Financeira pela Exploração Mineral), tal compensação é reconhecida também por royalties da mineração, objeto central deste estudo. 
Dossiê: Impactos e repercussões territoriais de empreendimentos na Pan-Amazônia | Gestão do território: análise econômica da mineração nos municípios da Amazônia Oriental paraense (2010 a 2017)|

| Gláucia Rodrigues Nascimento Medeiros | Marcus Vinicius Batella Medeiros |Luana Faria Medeiros |

Mas não se pode desconsiderar também qual o "preço da riqueza" já salientado por Altvater (1995), onde o autor sinalizava alguns fatores preocupantes em relação à sistematização utilizada já naquele período, principalmente em relação ao aumento de produtividade, quando se busca a criação de condicionantes relacionadas ao desenvolvimento.

Para Altvater (1995, p. 63):

\begin{abstract}
Portanto, o desenvolvimento pode ser interpretado como um esforço social de sistematização, de produção de coerência na economia, na sociedade, na política na cultura, com um duplo objetivo. No input do processo de desenvolvimento, os agentes sociais precisam ocupar-se das restrições econômicas, ecológicas ou políticas, e no output, precisam poder aumentar a produtividade para aumentar a riqueza.
\end{abstract}

Tal fenômeno salientado pelo autor ilustra a realidade vivida e sentida pela sociedade, onde as tomadas de decisão são realizadas pelo Congresso Nacional, representado pela classe política, apresentando de maneira mais evidenciada as relações de poder nessa segunda metade do ano de 2017. Seus atos e decisões se apresentam através de Medidas Provisórias, Decretos e outros artifícios buscando atender aos interesses pessoais, políticos, capitalistas e globais.

Outra característica observada na gestão territorial quando se realiza uma análise socioeconômica principalmente no plano nacional, se refere à desordem encontrada, principalmente quando se pensa que o Brasil está inserido em uma “(des)ordem mundial” seguindo a ótica de Altvater (1995).

Para o autor, o conceito de (des)ordem mundial é um resultado das concepções realizadas por ele (Altvater) quando afirma a não existência de caos sem ordem e consequentemente a inexistência de ordem sem caos, tudo irá depender da profundidade de análise, da escala utilizada na análise propriamente dita e da escolha do objeto de estudo, pois dependendo da perspectiva escolhida, possivelmente surgirá diversas ordens e desordens, ou melhor, dizendo, caos ordenados, ou consequentemente ordens caóticas, tudo dependerá da análise escalar da pesquisa e/ou da metodologia utilizada.

Tais mudanças realizadas no território seguem uma ordem voltada aos interesses mundiais, que de tempos em tempos sofre uma mutação e mudanças de denominação, onde no século XXI é denominado globalização. Tal movimento de expansão econômica global de acordo com Rodrik (2011) se tornou bastante evidente em vários momentos: Apogeu do Ouro no final do século XIX, as duas Guerras Mundiais, a diminuição dos custos dos trens e navios a vapor, e também influenciaram o comércio e a imigração. As 
Dossiê: Impactos e repercussões territoriais de empreendimentos na Pan-Amazônia | Gestão do território: análise econômica da mineração nos municípios da Amazônia Oriental paraense (2010 a 2017)|

| Gláucia Rodrigues Nascimento Medeiros | Marcus Vinicius Batella Medeiros |Luana Faria Medeiros | causas são cíclicas, mudando um contexto ou outro, mas os resultados são bem semelhantes.

Rodrik (2011) também salienta algumas mudanças do passado para a globalização atual, dentre elas o autor apresenta alguns fatores diferentes:

\begin{abstract}
Em primeiro lugar, as restrições à imigração não eram tão comuns durante $\mathrm{o}$ século XIX e, consequentemente, a mobilidade internacional da mão de obra foi mais comparável àquela do capital. Por isso, a assimetria entre o capital móvel (físico e humano) e a mão de obra "natural", "imóvel", que caracteriza a situação presente, é um fenômeno relativamente recente. Em segundo lugar, houve pouca competição internacional direta em produtos idênticos ou similares durante o século XIX, e a maior parte do comércio consistia no intercâmbio de produtos não concorrentes, como produtos primários por bens manufaturados. As relações comerciais agregadas não refletem o "grande aumento na exposição de indústrias de bens comercializáveis à competição internacional" que está ocorrendo agora em comparação com a situação na década de 1890. Em terceiro lugar, e talvez o mais importante, os governos ainda não foram convocados a desempenhar funções de previdência social em larga escala, como assegurar níveis de emprego adequados, estabelecer redes de segurança social, proporcionar seguros médicos e sociais e cuidar dos pobres (RODRIK, 2011, p. 12-13).
\end{abstract}

Pelo contrário, de acordo com as mudanças previstas na legislação do Brasil, os governos diminuirão ainda mais as responsabilidades perante a sociedade, retirando direitos antes reconhecidos, de acordo com as reformas trabalhistas e previdenciárias.

O que se observa são movimentos que devem ser analisados com muita atenção, devido aos danos que causarão através dos impactos negativos que comprometerão as gerações futuras.

Rodrik (2011) ainda salienta para as implicações que o peso de decisões erradas poderá causar principalmente nas decisões relacionadas à integração econômica internacional, onde o autor diz que o segredo está nas ações criativas, inteligentes e na dosagem dos formuladores das regras políticas, referentes à ação positiva.

Fazendo uma análise preliminar, nossos formuladores políticos, não estão sendo criativos e pouco menos inteligentes em relação às políticas econômicas internacionais, pois o Brasil está passando por um processo de retração econômica, podendo ser observada nos dados do PIB e nos Índices de Qualidade de Vida.

Em meio a tantas mudanças o Governo Federal através de medidas provisórias sancionou mudanças referentes à economia no setor mineral, prevendo maior arrecadação de impostos e compensações no setor, visando "incrementar" as receitas públicas em todas as esferas federais. Um desses incrementos se refere à Compensação Financeira pela Exploração dos Recursos Minerais (CFEM) ou royalties da mineração, onde os movimentos se referem à liberação de novos títulos minerários, liberação de lavras em terras raras, 
Dossiê: Impactos e repercussões territoriais de empreendimentos na Pan-Amazônia | Gestão do território: análise econômica da mineração nos municípios da Amazônia Oriental paraense (2010 a 2017)|

| Gláucia Rodrigues Nascimento Medeiros | Marcus Vinicius Batella Medeiros |Luana Faria Medeiros | abertura ao mercado investidor internacional, extinção de reservas antes vistas como ambientais, mas que hoje são revistas como sendo um potencial energético, estratégico e econômico.

\section{ENTENDENDO A CFEM}

Fazendo uma breve conceituação, de acordo com a Confederação Nacional dos Municípios (CNM), a CFEM é uma compensação financeira advinda da Exploração dos Recursos Minerais, utilizada como uma forma de contraprestação em decorrência da utilização de atividades econômicas dos recursos minerais nos territórios, ou seja, pode ser considerada como uma forma de contrapartida paga pelas empresas buscando compensar financeiramente os Municípios, Estados e União pelos impactos no território decorrente da exploração mineral.

A CFEM foi criada através da Constituição de 1988, no Capitulo II, Art. 20 que trata sobre os bens da União, onde estabelece:

$\int 1^{\circ}$ É assegurada, nos termos da lei, aos Estados, ao Distrito Federal e aos Municípios, bem como a órgãos da administração direta da União, participação no resultado da exploração de petróleo ou gás natural, de recursos hídricos para fins de geração de energia elétrica e de outros recursos minerais no respectivo território, plataforma continental, mar territorial ou zona econômica exclusiva, ou compensação financeira por essa exploração (BRASIL, 1988, p. 27).

Para exemplificar a importância desta compensação para a economia paraense, somente o estado do Pará arrecadou em quase sete anos (01/2010 - 07/2017) o valor total de R \$ 3.971.668.906,73 (Três bilhões, novecentos e setenta e um milhões, seiscentos e sessenta e oito mil, novecentos e seis reais e setenta e três centavos), representando $9 \%{ }^{1}$ do Produto Interno Bruto em valores correntes.

Os quase quatro bilhões de reais referentes à arrecadação estadual relativa aos municípios produtores minerais do Pará, apresentado pelo Departamento Nacional de Produção Mineral (DNPM) em quase sete anos de mineração (01/2010 à 07/2017), o DNPM apresentou que Parauapebas foi o município responsável por este volume arrecadado de CFEM, liderando por todo o período o ranking dos municípios mineradores, arrecadando um total de $\mathrm{R} \$ 2.861 .097 .233,00$ (dois bilhões, oitocentos e sessenta e um milhões, noventa e sete mil e duzentos e trinta e três reais) em compensação,

\footnotetext{
1 PIB Nacional em valores correntes dos anos de 2010 a 2016. O IBGE até o momento não publicou os
} valores referentes ao ano de 2017, até 2016 o valor foi de 36.456 bilhões de reais. 
Dossiê: Impactos e repercussões territoriais de empreendimentos na Pan-Amazônia | Gestão do território: análise econômica da mineração nos municípios da Amazônia Oriental paraense (2010 a 2017)|

| Gláucia Rodrigues Nascimento Medeiros | Marcus Vinicius Batella Medeiros |Luana Faria Medeiros | cerca de 44,08 \% dos royalties paraenses. Mais adiante serão apresentados os dados contendo os cinco municípios que mais arrecadaram em compensações no estado do Pará e seus respectivos valores.

Embora os valores arrecadados em CFEM sejam expressivos para a economia nacional, o lócus da pesquisa se restringe ao desenvolvimento econômico do estado do Pará, em especial, dos municípios de Parauapebas e Canaã dos Carajás, devido suas riquezas naturais e os altos índices de compensações financeiras arrecadadas, contrastando com os índices de desenvolvimento dos municípios, surgindo preocupações sobre quais os impactos negativos que serão intensificados ao longo dos anos a partir da criação da ANM e os possíveis impactos decorrentes das mudanças previstas nas Medidas Provisórias (MPs) de número 789, 790 e 791, todas de 25 de julho de 2017.

Como metodologia de pesquisa, foi utilizada uma análise quantitativa e qualitativa, sistematizada aos indicadores socioeconômicos, visando mensurar os Índices de Desenvolvimento Municipal, possibilitando uma melhor identificação das problemáticas que impedem o pleno desenvolvimento do estado e dos municípios paraenses, juntamente com os dados do Instituto Brasileiro de Geografia e Estatística (IBGE), Índice Firjan, Departamento Nacional de Produção Mineral (DNPM), Constituição Federal, Banco Central, Ministério de Minas e Energia, Ministério do Meio Ambiente, Instituto Chico Mendes de Conservação da Biodiversidade (ICMBio), artigos científicos, periódicos, entre outros.

Buscando uma visão mais holística e um entendimento sistêmico, sobre os impactos nos territórios com atividades econômicas do setor mineral no Pará, em especial nos municípios de Parauapebas e Canaã dos Carajás, se faz necessário um entendimento prévio sobre o montante arrecadado no estado paraense, buscando analisar o peso da CFEM tanto para o Governo Estadual quanto para os municípios de Parauapebas e Canaã dos Carajás, buscando também realizar uma reflexão sobre o montante arrecadado pelos entes federados e o quanto esses valores de fato agregaram valor no desenvolvimento regional no Estado e nos municípios paraenses.

A partir deste entendimento, pretende-se também gerar uma reflexão e fomentar estudos futuros sobre as intencionalidades do Governo Federal através do Ministério de Minas e Energia em alterar a regulação no setor mineral a partir das MPs nº 789, 790 e 791 analisando quais os impactos futuros que o Estado do Pará e os Municípios de Parauapebas e Canaã dos Carajás enfrentarão a partir dessas mudanças, tendo em vista, o Pará ser 
Dossiê: Impactos e repercussões territoriais de empreendimentos na Pan-Amazônia | Gestão do território: análise econômica da mineração nos municípios da Amazônia Oriental paraense (2010 a 2017)|

| Gláucia Rodrigues Nascimento Medeiros | Marcus Vinicius Batella Medeiros |Luana Faria Medeiros | possuidor de terras com as maiores riquezas naturais, poder energético, diversidade, importante potencial econômico e estratégico para o país.

O fator que merece mais atenção é a falta de autonomia e ausência de participação do Governo Estadual e dos municípios do Pará no poder decisório em relação às regras imputadas em seus territórios, onde o Governo Federal se ampara na Constituição Federal de 1988 no artigo 20 no item IX: “os recursos minerais, inclusive os do subsolo”, tendo em vista, que de acordo com a interpretação, a União é a representante legal da natureza e seus recursos, deixando os Estados e Municípios apenas com a participação no resultado (Taxas, Impostos e Compensações), não se estendendo ao poder decisório.

Tal interpretação se mantém devido todos os recursos no solo e subsolo pertencerem a União, inclusive as terras indígenas, pois são considerados recursos energéticos e/ou estratégicos em todo território nacional, justificada na Carta Magna como sendo importante para a soberania nacional.

\section{O PIB NACIONAL E PIB PER CAPITA DOS MUNICÍPIOS}

De acordo com o IBGE o Brasil vem apresentando um crescimento em relação ao Produto Interno Bruto Nacional, onde a cada ano suas receitas recebem um incremento de milhões de reais. Mas esse crescimento vem apresentando uma desaceleração considerável no acumulado, onde no ano base (2010) o PIB Nacional foi de 3.886 Bilhões de reais, chegando em 2016 com o valor de 6.267 Bilhões de reais conforme Quadro 01:

Quadro 01 - PIB VALORES CORRENTES - BRASIL - 2010 a 2016
\begin{tabular}{|c|r|}
\hline ANO & VALOR (Em Bilhões de Reais) \\
\hline 2010 & 3.886 \\
\hline 2011 & 4.376 \\
\hline 2012 & 4.815 \\
\hline 2013 & 5.332 \\
\hline 2014 & 5.779 \\
\hline 2015 & 6.001 \\
\hline 2016 & 6.267 \\
\hline TOTAL & \\
\hline
\end{tabular}

Conforme Quadro 01, o PIB Nacional teve um aumento nesses seis anos, porém seu ápice ocorreu entre os anos de 2012 a 2013, apresentando um aumento de 513 milhões de reais. Seu pior desempenho ocorreu entre os anos de 2014 a 2015, crescendo apenas 222 
Dossiê: Impactos e repercussões territoriais de empreendimentos na Pan-Amazônia | Gestão do território: análise econômica da mineração nos municípios da Amazônia Oriental paraense (2010 a 2017)|

| Gláucia Rodrigues Nascimento Medeiros | Marcus Vinicius Batella Medeiros |Luana Faria Medeiros | milhões de reais. Entre os anos de 2015 a 2016 o crescimento também não foi expressivo conforme os anos anteriores, crescendo apenas 266 milhões de reais. Esse crescimento escalar pode ser visualizado no Gráfico 01:

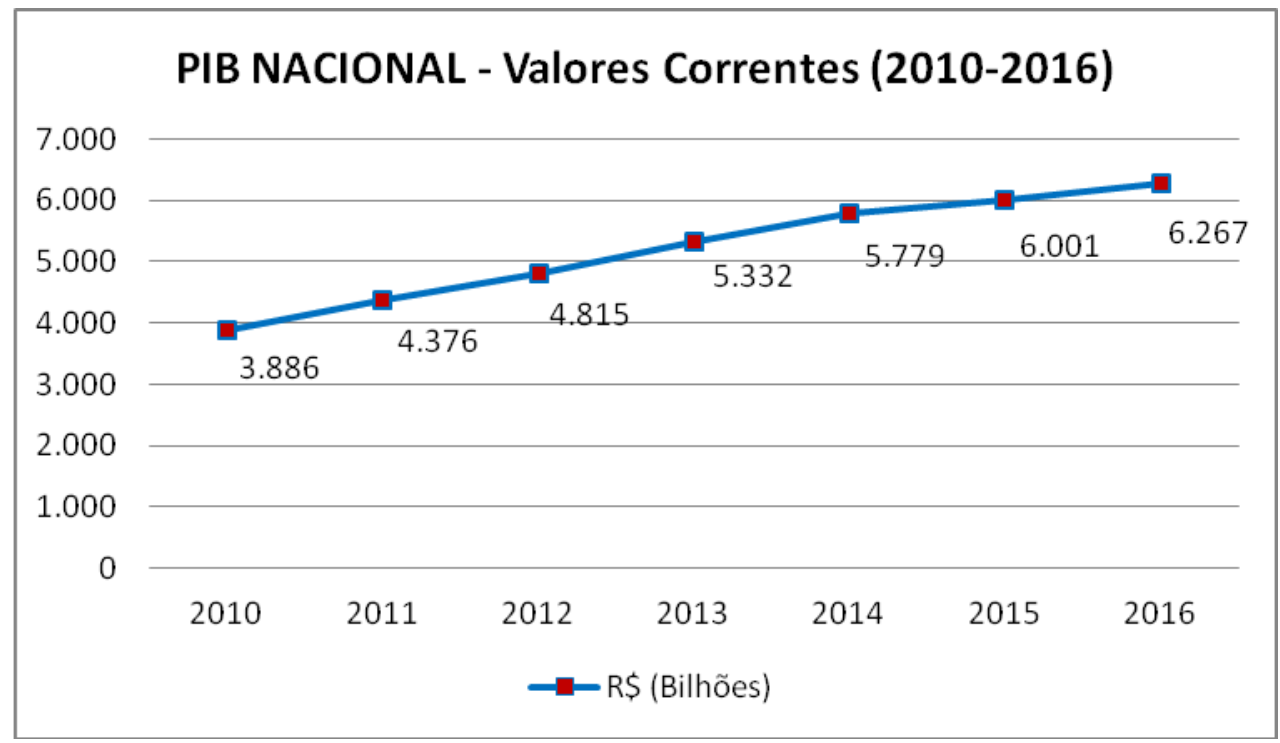

Gráfico 01 - PIB NACIONAL - Valores Correntes (2010 - 2016).

Fonte: IBGE (2017).

Conforme Gráfico 01, o incremento no PIB NACIONAL apresentou um crescimento expressivo entre os anos de 2010-2011; 2011-2012; 2012-2013 e; 2013-2014, sendo superiores a 400 milhões de reais. Os valores começaram a cair entre os anos de 2014-2015, fechando o ano com um crescimento de 222 milhões de reais e 2015-2016 com um crescimento de 266 milhões de reais. Embora o PIB tenha crescido, houve uma variação negativa, fazendo o PIB despencar apresentado no Gráfico 02.

A elevação do PIB serve como um indicador para a Geografia como sendo uma latente estratégia de intervenção do Estado frente ao poder decisório em relação aos recursos naturais, principalmente quando se tem energias estratégicas em solo Amazônico, como fator preponderante para esse contínuo crescimento.

Conforme Ribeiro (2016):

A construção do espaço amazônico, ao longo de sua história, foi se processando através de um conjunto de mecanismos político-jurídico gestado e coordenado pelo Estado, como parte de uma política territorial com visita e garantia de seus espaços internos. Para isso, o Estado sempre teve como fundamento sua concepção de espaço nacional que conjuga uma estratégia intervencionista, tanto ao nível da estrutura de seu território, quanto à gestação dos instrumentos necessários à viabilização dessa política (RIBEIRO, 2016, p. 35). 
Dossiê: Impactos e repercussões territoriais de empreendimentos na Pan-Amazônia | Gestão do território: análise econômica da mineração nos municípios da Amazônia Oriental paraense (2010 a 2017)|

| Gláucia Rodrigues Nascimento Medeiros | Marcus Vinicius Batella Medeiros |Luana Faria Medeiros |

Desse modo, se fará um entendimento que o PIB neste caso seja um instrumento utilizado pelo Estado para intervir na política territorial, gerando indicadores para garantir o seu pleno domínio e garantir os espaços internos, traduzidos nesse caso, como às riquezas naturais encontradas no solo e subsolo.

Para ilustrar a intervenção do Estado, o Gráfico 02, apresentará que embora o PIB esteja aumentando, seu percentual de acúmulo vinha diminuído, onde nos últimos anos, as ações intervencionistas do Estado, buscam manter o controle total das finanças públicas, apresentando em 2016 uma pequena variação positiva em comparação com os anos de anteriores.

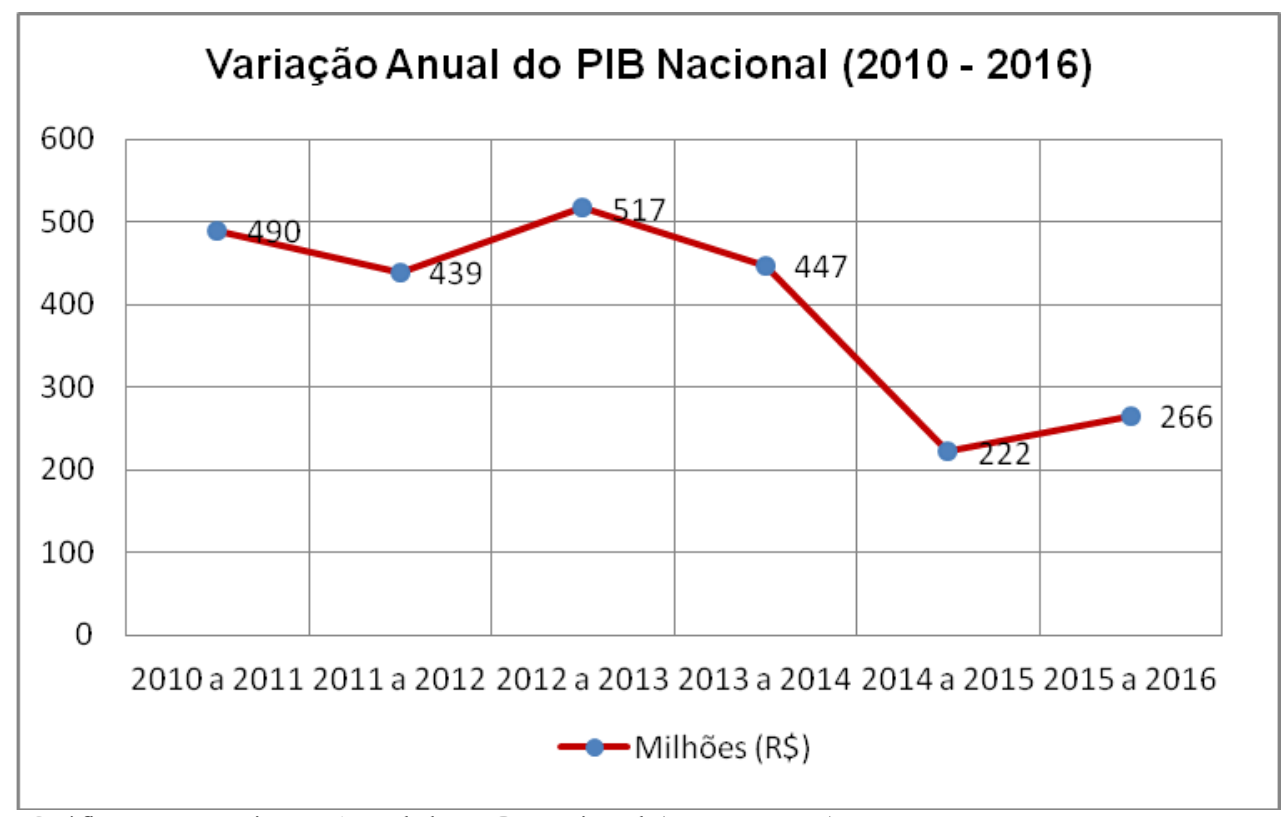

Gráfico 02 - Variação Anual do PIB Nacional (2010 - 2016)

Fonte: IBGE (2017).

Embora o PIB Nacional esteja demonstrando um crescimento, sua variação ano após ano, vêm apresentando um decréscimo em relação aos anos anteriores, dando possíveis sinais que algum setor do país esteja declinando, tendo em vista a que o melhor resultado foi conquistado entre os anos de 2012 a 2013, fechando o PIB Nacional em 517 milhões de reais. Em comparação com o período de 2015 a 2016, já considerando a discreta alta em comparação com o ano anterior, o valor do PIB Nacional foi de 266 milhões de reais, representando uma diferença de 51,45\% em relação ao melhor período analisado.

Quando se analisa os municípios de Parauapebas e Canaã dos Carajás, o IBGE não disponibiliza os dados referentes ao PIB Per Capita dos Municípios até ao ano de 2016, os dados vão até ao ano de 2014. 
Dossiê: Impactos e repercussões territoriais de empreendimentos na Pan-Amazônia | Gestão do território: análise econômica da mineração nos municípios da Amazônia Oriental paraense (2010 a 2017)|

| Gláucia Rodrigues Nascimento Medeiros | Marcus Vinicius Batella Medeiros |Luana Faria Medeiros |

Embora os municípios de Parauapebas e Canaã dos Carajás tenham apresentado em sua última avaliação uma queda considerável em relação ao período anterior no PIB Per Capita Municipal, conforme Gráfico 03, o município de Canaã dos Carajás apresentou uma melhor situação nos anos de 2010 a 2014 em comparação com o município de Parauapebas. Essa informação chama a atenção tendo em vista a arrecadação da CFEM em Parauapebas ser infinitamente maior que Canaã dos Carajás, onde mais adiante veremos os gráficos.

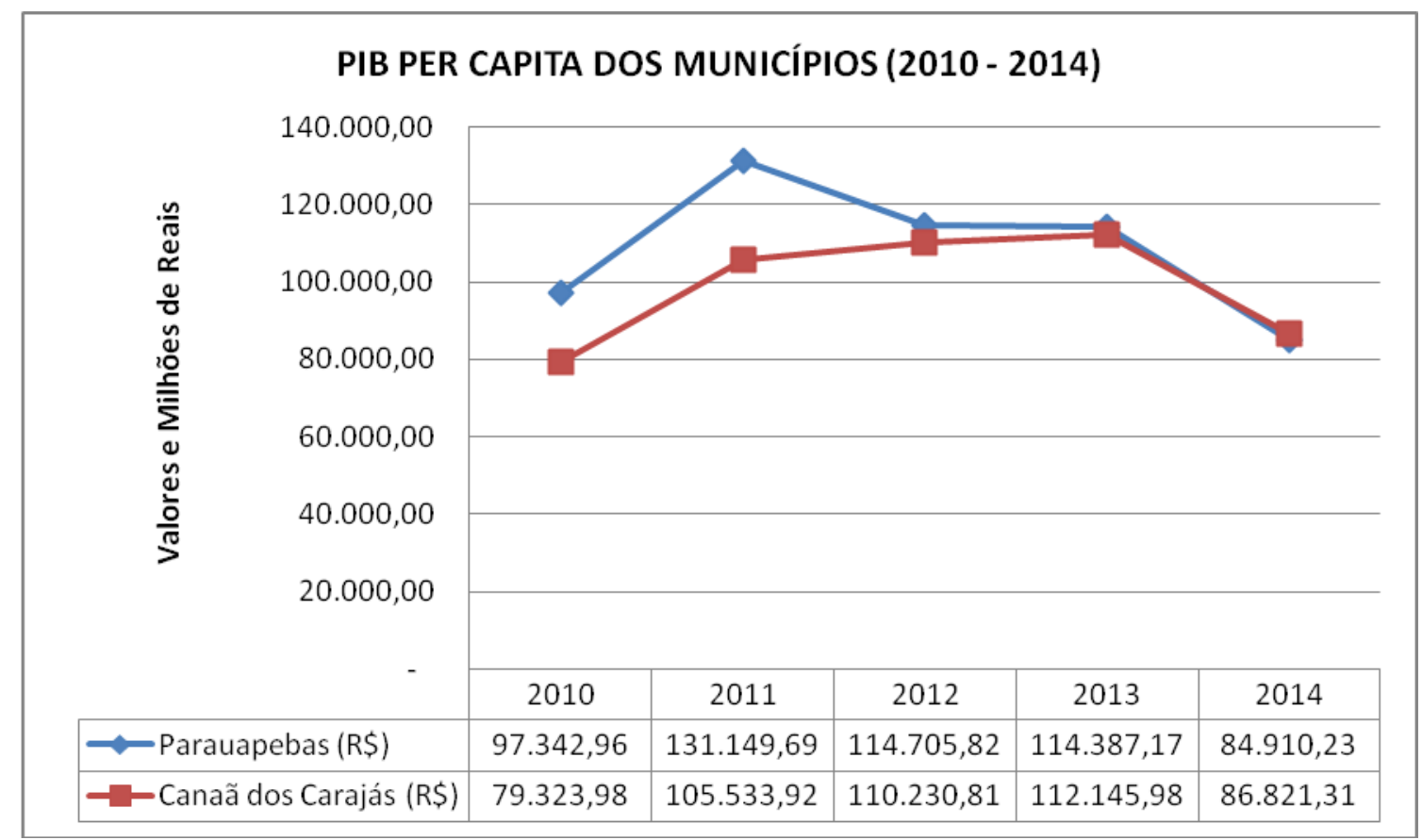

Gráfico 03 - PIB Per Capita dos Municípios (2010 - 2014).

Fonte: IBGE (2017).

Outro dado importante analisado no Gráfico 02 se refere a pouca diferença entre PIB Per Capita entre os Municípios de Parauapebas e Canaã dos Carajás. Embora ambos possuam receitas e compensações bem diferentes, o PIB Per Capita de Parauapebas não reflete o montante acumulado, chegando em 2014 ser inferior ao do município de Canaã dos Carajás.

Em relação ao quantitativo populacional de acordo com o IBGE em seu último Censo (2010) Parauapebas contava com aproximadamente 153.908 pessoas, e uma densidade demográfica de 22,35 hab $/ \mathrm{km}^{2}$ e uma estimativa para 2016 de 196.259 pessoas.

Em Canaã dos Carajás, de acordo com o Censo 2010 (IBGE), o município possuía um quantitativo de 26.716 pessoas, com uma densidade demográfica de 8,49 hab $/ \mathrm{km}^{2}$. Na estimativa para o ano de 2016, esse número subiu para 34.853 pessoas. De acordo com 
Dossiê: Impactos e repercussões territoriais de empreendimentos na Pan-Amazônia | Gestão do território: análise econômica da mineração nos municípios da Amazônia Oriental paraense (2010 a 2017)|

| Gláucia Rodrigues Nascimento Medeiros | Marcus Vinicius Batella Medeiros |Luana Faria Medeiros | informações levantadas no portal da Prefeitura de Canaã dos Carajás, a estimada hoje é de cerca de 50 mil habitantes.

Considerando o montante arrecadado através da produção mineral em Parauapebas e Canaã dos Carajás, refletindo na expressiva diferença entre arrecadações da CFEM, esses valores destoam entre o PIB Per Capita dos Municípios de estudados, surgindo questionamentos quanto à própria informação fornecida pelo IBGE referentes ao PIB dos Municípios.

Levando em consideração que o PIB dos Municípios ser um sistema criado pelo IBGE, buscando avaliar os indicadores municipais, referentes às informações econômicas e sociais, sua importância se torna questionável no momento que o instrumento não se traduz de fato a realidade local, onde se faz necessário o levantamento de todas as receitas municipais. A ausência dos indicadores referentes à CFEM comprometendo um efetivo planejamento de políticas públicas e uma contínua avaliação dos resultados das ações realizadas no território através das políticas públicas municipais e estaduais.

Consequentemente, a ausência desse indicador de qualidade no IBGE prejudica não somente a responsabilidade socioeconômica na gestão pública de uma maneira geral, como fere a autonomia dos estados e municípios, pois o instrumento não é capaz de apresentar e ampliar as demandas necessárias para a efetiva produção do espaço urbano, referentes aos dados econômicos e sociais, pois a padronização dos dados municipais realizadas pelo IBGE, por exemplo, se mostrou frágil, e a médio e longo prazo compromete a análise geográfica espacial e estatística, pois não vislumbra as especificidades territoriais, principalmente em municípios com algum tipo de compensação mineral, se mantendo apenas a um resultado quantitativo e mesmo assim com ressalvas.

A importância de dados atualizados é a base para a pesquisa geográfica, pois é através de tais informações que o pesquisador da Geografia se baseia para realizar suas análises acerca dos fenômenos encontrados no espaço vivido.

Nesta etapa da pesquisa cabe uma reflexão sobre a concepção de espaço de Carlos (2011), para ratificar a importância em se ter uma base de dados Estatísticos e Geográficos atualizados no século XXI, para que os indicadores possam ser considerados indicadores de desempenho e ferramenta de auxílio para a tomada de decisões.

Para Carlos (2011):

$\mathrm{Na}$ Geografia, a noção de espaço, com muita dificuldade supera sua condição de objetividade pura. Não resta dúvida de que a evolução do conceito de espaço como localização dos fenômenos, para aquele de "produção social" é um salto expressivo em direção à compreensão do mundo através da Geografia, 
Dossiê: Impactos e repercussões territoriais de empreendimentos na Pan-Amazônia | Gestão do território: análise econômica da mineração nos municípios da Amazônia Oriental paraense (2010 a 2017)|

| Gláucia Rodrigues Nascimento Medeiros | Marcus Vinicius Batella Medeiros |Luana Faria Medeiros |

permitindo-nos pensar na passagem de uma concepção a outra, como momentos de transformação da realidade. É assim que da simples constatação da localização das coisas no espaço passa-se à descoberta da "organização do espaço" pelos grupos humanos e, desta elaboração, para a ideia de que a sociedade produz seu próprio espaço. Portanto há um movimento na constituição do pensamento geográfico que, ao longo de sua história, permite caminhar do conceito de localização das atividades na superfície da terra ao de organização do espaço pelo grupo humano, para pensar os conteúdos dos processos constitutivos do espaço - sua natureza e sentido (CARLOS, 2011, p. 59).

De acordo com Carlos (2011), a produção social sob a ótica da Geografia necessita antes de tudo, de uma efetiva localização dos fenômenos, buscando com esse movimento pensar e mudar as concepções de realidade. O IBGE realiza o Censo a cada 10 anos e as informações adicionadas ano após ano, se encontram defasadas, prejudicando a leitura ostensiva e objetiva dos fenômenos socioeconômicos, com isso, a análise da pesquisa se torna comprometida, onde consequentemente direciona a pesquisa para uma falsa leitura de realidade.

A ineficiente identificação das problemáticas vividas nos territórios, principalmente em espaços que precisam de constantes avaliações de desempenho, comprometem as tomadas de decisão, pois são baseadas em indicadores de avaliação de desempenho defasados, e tendo como resultado, ações equivocadas, pois não consideram os lapsos temporais nas informações aos quais foram baseadas, desconsiderando também as relações de poder, geradoras de territorialidades e territorialização, devido à multiplicidade espacial.

De acordo com Raffestin (1993), a territorialidade possui um valor diferenciado, devido a as múltiplas dimensões vividas e produzidas pelo coletivo, principalmente por estarem inseridos em um processo e produto vividos, sentidos e reproduzidos no território.

A obsolescência nas avaliações de desempenho prejudica também a continuidade evolutiva e necessária de ações voltadas ao desenvolvimento regional, principalmente quando se busca incrementar a geração de renda, através de atividades econômicas objetivas, ou melhorar as questões ambientais, entre outros, ou seja, as obsolescências dos resultados de avaliação de desempenho não são compatíveis com a melhoria contínua do bem-estar social, comprometendo também a governança pública.

Vale ressaltar que a ineficiência de indicadores de avaliação de desempenho influenciam diretamente os padrões de interação entre os poderes do Governo (Executivo, Legislativo e Judiciário), bem como, a competência de qual esfera (municipal, estadual ou federal) seria a responsabilidade por possíveis impactos negativos causados em um território, por exemplo, capazes inclusive de alterar os processos de inputs e de outputs, que neste caso, se pode utilizar a exemplificação de Couto (1998, p. 41-42): 
Dossiê: Impactos e repercussões territoriais de empreendimentos na Pan-Amazônia | Gestão do território: análise econômica da mineração nos municípios da Amazônia Oriental paraense (2010 a 2017)|

| Gláucia Rodrigues Nascimento Medeiros | Marcus Vinicius Batella Medeiros |Luana Faria Medeiros |

O governo é concebido por mim como algo não somente mais amplo do que o Poder Executivo - tal como é considerado na linguagem cotidiana e em grande parte da literatura especializada - mas também como algo distinto das estruturas políticas institucionais. Governo é concebido aqui como a função do sistema político atinente ao processo de conversão dos inputs (demandas e apoios) nos outputs do sistema (políticas governamentais dos mais diversos tipos). Portanto, as instituições estatais responsáveis pelo funcionamento dos sistemas políticos dentre as quais os Poderes Executivo e Legislativo - são estruturas incumbidas do cumprimento da função governamental, não se confundindo elas mesmas com o governo. Assim, tanto o Executivo não é sinônimo de governo como o Legislativo dele não está excluído.

De acordo com o exemplo supracitado, as decisões políticas possuem esse caráter difuso, onde por muitas vezes as decisões possuem como resultado uma ação arbitrária e ditatorial, principalmente quando os resultados negativos afetam a sociedade civil, pois prejudica os preceitos básicos defendidos na Constituição Federal de 1988. Ao fazer uma análise sucinta sobre o peso dessas decisões na contemporaneidade brasileira, constantemente os atos decisórios dos Poderes Executivos e Legislativos, e por que não incluir o Judiciário, perpassa os limites do ato e se confundem como sendo uma decisão de Governo, o que não é verdadeiro e tão pouco legítimo em um regime democrático de direito.

Couto (1998) ainda salienta:

No presidencialismo o relacionamento é mais complexo. Não apenas deixa de ocorrer uma fusão entre os dois Poderes como existe uma relação de externalidade competitiva entre eles, advinda de seu funcionamento e instituição independentes, o que pode ser aguçado, como no caso brasileiro, por um sistema multipartidário - muito embora também em presidencialismos bipartidários, como o norte-americano, a externalidade dos Poderes gere uma dinâmica competitiva entre eles, como alertam aqueles que trabalham com a ideia de "governo dividido". A externalidade tem consequências importantes para a eficácia governamental. Por um lado, não favorece a co-responsabilidade entre os Poderes, isto é, não os induz à cooperação em decorrência de incentivos institucionais; por outro, em virtude de ser o Executivo o responsável pela implementação das políticas de governo, aos olhos do público é ele que aparece como ente responsável pelo bom ou mau desempenho governamental, muito embora dependa do Parlamento para a tomada de uma ampla gama de decisões de governo (COUTO, 1998, p. 44).

A partir deste entendimento sobre a competência entre os Poderes, se torna possível o entendimento sobre as responsabilidades pelos impactos negativos advindos das decisões que impactam a gestão dos territórios, bem como, entender até que ponto determinado problema foi decorrente de uma decisão dos Poderes ou de Governo, em especial sobre as decisões acerca do setor mineral em Território Nacional, tanto no estado do Pará, quanto nos municípios impactados, em especial, Parauapebas e Canaã dos Carajás, surgindo questionamentos quanto à ineficiência dos recursos arrecadados pelos Estados, Municípios e União. 
Dossiê: Impactos e repercussões territoriais de empreendimentos na Pan-Amazônia | Gestão do território: análise econômica da mineração nos municípios da Amazônia Oriental paraense (2010 a 2017)|

| Gláucia Rodrigues Nascimento Medeiros | Marcus Vinicius Batella Medeiros |Luana Faria Medeiros |

\section{ARRECADAÇÕES DA CFEM NO BRASIL NO PERÍODO DE 2010 A 07/2017 E OS TÍTULOS}

Como a mineração é uma atividade econômica desenvolvida em diversos municípios do Brasil, onde democraticamente se arrecada a CFEM, de acordo com o DNPM, no sexto dia útil de cada mês, são recolhidos pelas empresas de mineração os valores diretamente para as respectivas contas correntes destinadas para este fim (CFEM), para os devidos entes federados.

Ainda de acordo com o DNPM, o recolhimento segue os seguintes percentuais: 65\% para o município, 23\% para o Estado de origem da extração e 12\% para a União. Tais percentuais não foram alterados pela União em 25 de julho de 2017, mas foram sancionadas as Medidas Provisórias: MP n ${ }^{\circ} 789$, MP $\mathrm{n}^{\circ} 790$ e MP $\mathrm{n}^{\circ} 791$, onde foram definidas novas regras para o setor mineral, dentre elas, a criação da Agência Nacional de Mineração (ANM) e a extinção do Departamento Nacional de Produção Mineral (DNPM) sancionadas na MP n ${ }^{\circ} 791$.

A decisão do Governo Federal em extinguir o DNPM, e na mesma Medida Provisória criar a ANM, pode ser classificada como: "Padrões de interação ExecutivoLegislativo”. Segundo Couto (1998, p. 45), para ser considerada como um padrão se faz necessário seguir três variáveis: referentes às estratégias, às modalidades e quais os elementos de troca.

Quanto a variável “estratégia”, Couto (1998) acredita que a interação pode seguir apenas os teores de cooperação ou em alguns casos, se apresenta de forma competitiva. $\mathrm{Na}$ variável "modalidade", se apresenta de forma estável através de alianças ou em formato de resistência; e na variável "elementos de troca", se apresentam de maneira instável através de negociatas pontuais, explicitamente sendo realizada pelo Governo Federal.

Em relação a MP no 789, que se trata de uma Medida Provisória criada exclusivamente para regular a CFEM, é importante observar os movimentos futuros a ser realizados pelos Poderes acerca das brechas que a própria MP deixa, devido sua importância e volume financeiro de arrecadação desta compensação para as receitas públicas.

Para mensurar a importância dessa compensação para os entes federados, o Gráfico 04 apresentará o ranking dos cinco principais Estados arrecadadores de CFEM do Brasil, juntamente com os valores arrecadados entre os anos de 2010 a 2017. 


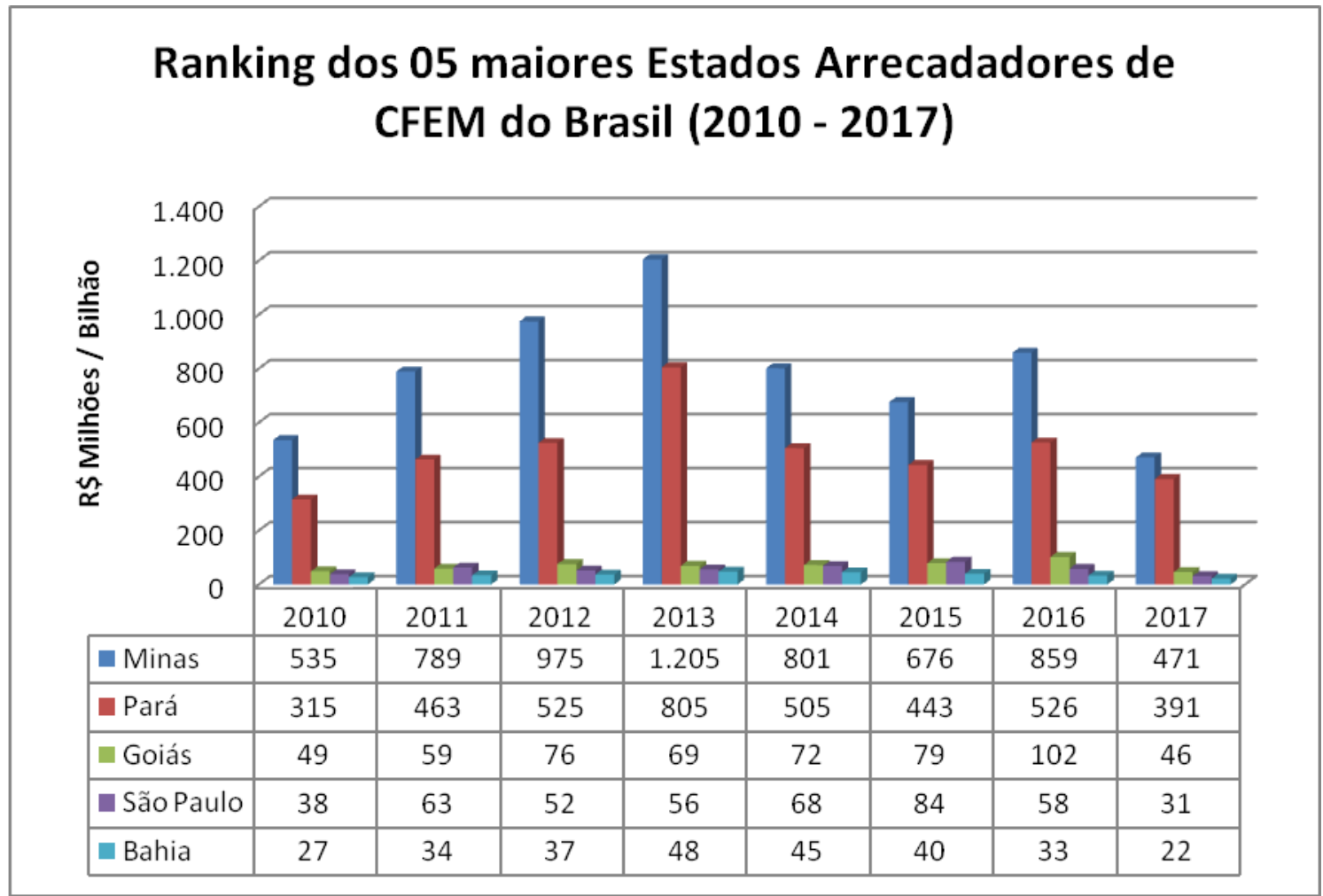

Gráfico 04 - Ranking dos cinco maiores arrecadadores de CFEM do País (2010 - 2017) Fonte: DNPM (2017).

De acordo com o Gráfico 04, ao longo dos sete anos de arrecadação, o estado de Minas Gerais permaneceu em primeiro lugar no ranking nacional dos estados arrecadadores de CFEM. Embora o estado do Pará tenha permanecido em segundo lugar, o estado têm anualmente diminuído a diferença de arrecadação em relação ao primeiro lugar, aparentemente por alguns fatores: $1^{\circ}$ pela diminuição de arrecadação de CFEM do estado de Minas Gerais a partir do ano de 2014; $2^{\circ}$ pela constância média em arrecadação do estado do Pará; $3^{\circ}$ pelo estado de Minas Gerais aparentemente apresentarem dificuldades em relação à quantidade de produção de minérios em suas minas, forçando o estado a aumentar a quantidade de títulos minerários, conforme Gráfico 05.

Já o Estado do Pará, se manteve estável quanto ao quantitativo de títulos, onde em 2010 possuía um quantitativo de 165, tendo seu ápice em 2015 contando com a quantidade de 305 títulos, chegando o mês de julho de 2017 com o quantitativo de 226 títulos. 

paraense (2010 a 2017)|

| Gláucia Rodrigues Nascimento Medeiros | Marcus Vinicius Batella Medeiros |Luana Faria Medeiros |

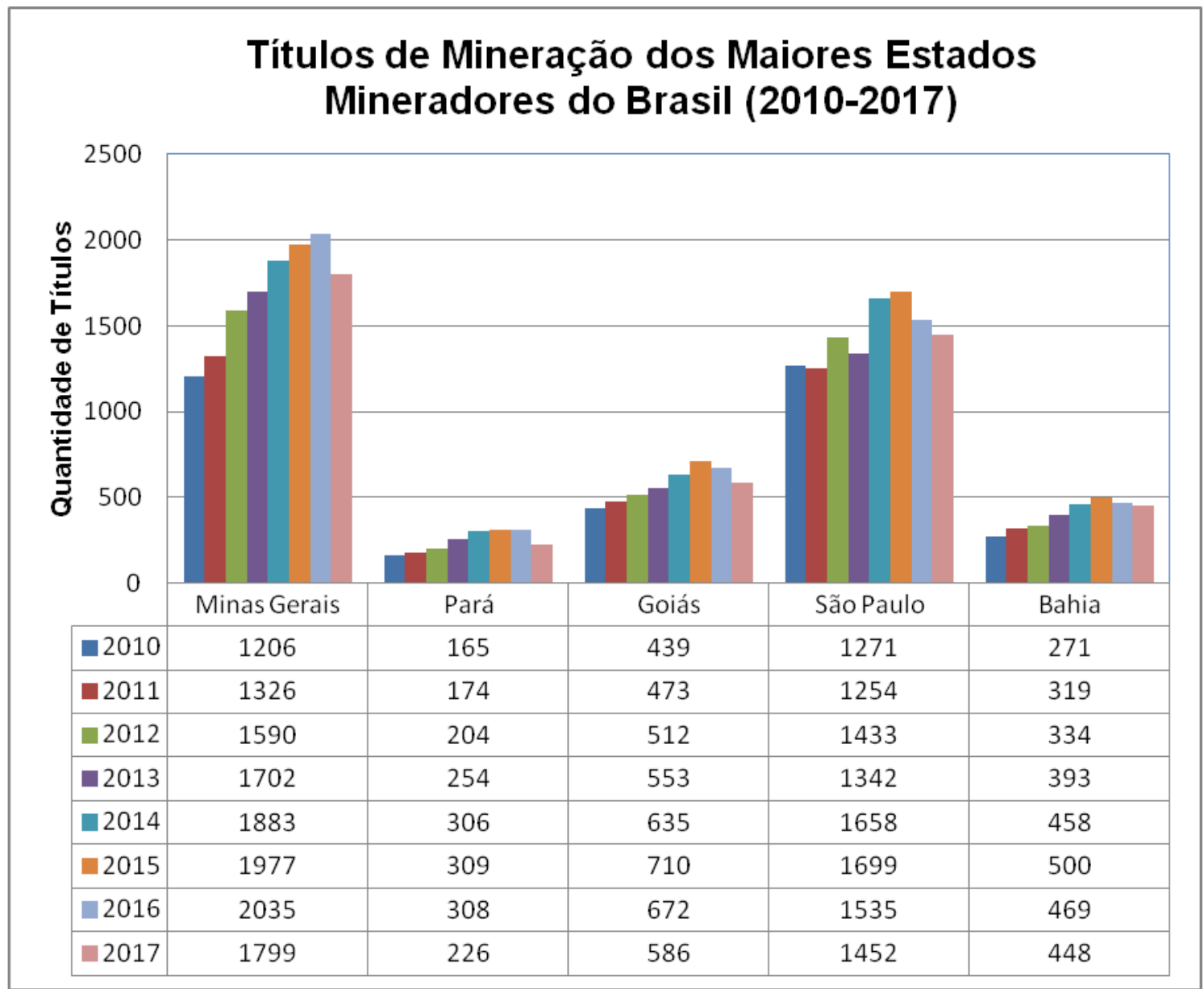

Gráfico 05 - Títulos de Mineração dos Maiores Estados Mineradores do Brasil (2010-2017)

Fonte: DNPM (2017).

De acordo com o Gráfico 05, em 2010 Minas Gerais possuía um valor já elevado de títulos minerários, contava com 1206 títulos, perdendo apenas para o estado de São Paulo que possuía 1271. Mas em relação a uma análise quantitativa, a quantidade elevada de títulos de São Paulo não se traduzia em aumento de arrecadação de CFEM, pois nesse ano o estado de São Paulo arrecadou apenas 38 milhões de reais. O estado do Goiás, por exemplo, possuía neste ano o quantitativo de 439 títulos, arrecadando um valor de 49 milhões de reais.

No ano de 2011, o estado de Minas Gerais incrementou a quantidade de 120 títulos, finalizando o ano com 1390 títulos. Esse aumento fez o estado arrecadar o valor de 790 milhões de reais. Já o estado do Pará, realizou um aumento quantitativo discreto, incrementando apenas nove títulos, com um somatório de 174 títulos em 2011, mas o valor de arrecadação de CFEM aumentou, subindo para 463 milhões. O estado de Goiás aumentou o quantitativo em 34 títulos, subindo a arrecadação para 59 milhões de reais. $\mathrm{O}$ estado de São Paulo diminuiu a quantidade de títulos para 1254, mas houve uma 
Dossiê: Impactos e repercussões territoriais de empreendimentos na Pan-Amazônia | Gestão do território: análise econômica da mineração nos municípios da Amazônia Oriental paraense (2010 a 2017)|

| Gláucia Rodrigues Nascimento Medeiros | Marcus Vinicius Batella Medeiros |Luana Faria Medeiros | arrecadação considerável, pois, o estado arrecadou 64 milhões, onde o valor arrecadado foi conquistado com menos 25 títulos.

No ano de 2012, Minas Gerais subiu para 1590 títulos, aumentando em 264 títulos, subindo a arrecadação para 975 milhões de reais. No Pará, houve um aumento de 30 títulos, e esse aumento elevou a arrecadação de CFEM para 525 milhões de reais. São Paulo elevou seus títulos para 1433, incrementando em 174 títulos a mais em relação ao período anterior, embora tenha aumentado à quantidade de títulos, a arrecadação foi menor que ao ano anterior, fechando o período com 52 milhões de reais.

No ano de 2013, Minas Gerais aumentou em 112 títulos, gerando uma arrecadação de 1 bilhão e 205 milhões de reais, o melhore resultado em arrecadação de CFEM do período. Já o Pará aumentou em 50 títulos, gerando uma arrecadação de 805 milhões de reais. São Paulo diminuiu para 1342 títulos, contando com menos 91 títulos, fechando o ano com uma arrecadação de 26 milhões de reais.

O ano de 2016 foi o período que Minas Gerais, liberou títulos, chegando ao número de 2035, gerando uma arrecadação de 859 milhões de reais em CFEM. Para aumentar sua produção mineral, o Pará subiu par a 308 títulos, sendo inferior em quantidade em comparação ao ano de 2015 que foi de 309. O aumento quantitativo gerou em arrecadação de CFEM o valor de 529 milhões de reais. O estado de São Paulo possuía 1535 títulos, arrecadando no ano em CFEM apenas 58 milhões de reais, quase 10 vezes menos que o estado do Pará, contanto com uma quantidade de quase cinco vezes mais de títulos que o estado do Pará.

Conforme os gráficos 04 e 05 se fazem necessárias algumas reflexões acerca da importância do Pará para a economia nacional. É correto afirmar o poder econômico que o estado do Pará possui, advindo do setor mineral, pois a qualidade do solo e subsolo potencializa não somente a produção mineral, como também, a arrecadação financeira. É correto afirmar também que o estado paraense tem se mostrado conservador e tímido frente aos outros estados produtores, quanto à liberação de novos títulos, e também podemos arriscar a possibilidade que este quadro mudará nos próximos anos a partir da criação da ANM e implantação das mudanças nas regras de compensações financeiras advindas da CFEM, podendo possivelmente colocar o estado paraense pela primeira vez como o maior produtor mineral e arrecadador de CFEM.

Embora o estado do Pará esteja a anos ocupando o segundo lugar na arrecadação de CFEM, esse feito não foi construído pelo coletivo de municípios, ou seja, adveio em sua forma mais expressiva de um único município, Parauapebas. Mas esse quadro nos 
Dossiê: Impactos e repercussões territoriais de empreendimentos na Pan-Amazônia

| Gestão do território: análise econômica da mineração nos municípios da Amazônia Oriental paraense (2010 a 2017)|

| Gláucia Rodrigues Nascimento Medeiros | Marcus Vinicius Batella Medeiros |Luana Faria Medeiros | próximos anos tende a mudar, através da criação do Complexo Minerador S11D - Eliezer Batista, colocando Canaã dos Carajás em primeiro lugar devido ao potencial energético de altíssimo teor de qualidade no minério de ferro.

\section{ARRECADAÇÕES DA CFEM PARA O ESTADO DO PARÁ E PARA OS MUNICÍPIOS DE PARAUAPEBAS E CANAÃ DOS CARAJÁS NO PERÍODO DE 2010 A 07/2017}

De acordo com os números apresentados no DNPM, Parauapebas é um município que deve ser observado pela União e pelo Governo Estadual de maneira diferenciada, pois somente ele que gera as maiores arrecadações em royalties para os cofres públicos.

Embora Parauapebas seja o município responsável por grande parte das arrecadações estaduais e nacionais, sua importância não reluz aos níveis de investimento e desenvolvimento esperado para um município desta magnitude, contrastando com os baixos índices de qualidade de vida e bem-estar social, quando comparado aos montantes arrecadados pelo município e o estado. A pobreza pode ser vislumbrada na paisagem da cidade, devido à falta de investimentos em infraestrutura, educação, saúde e qualidade ambiental, o que tem intensificado os conflitos e incrementando a cada ano a violência municipal devido à falta de investimento na segurança pública. A análise dos indicadores de avaliação de desempenho não são objetos desse estudo, mas a constatação foi realizada em trabalho de campo realizada ao município em 2015 e 2016, apresentado em Defesa de Dissertação de Mestrado² no ano de 2016.

\footnotetext{
2 Dissertação de Mestrado defendida por Gláucia Rodrigues Nascimento Medeiros na Universidade Federal do Pará (UFPA), vinculada ao Programa de Pós-graduação em Geografia (PPGeo) em agosto de 2016, financiada com recursos da CAPES, intitulada: Gestão do Território e Responsabilidade Social das Empresas de Mineração no Estado do Pará.
} 


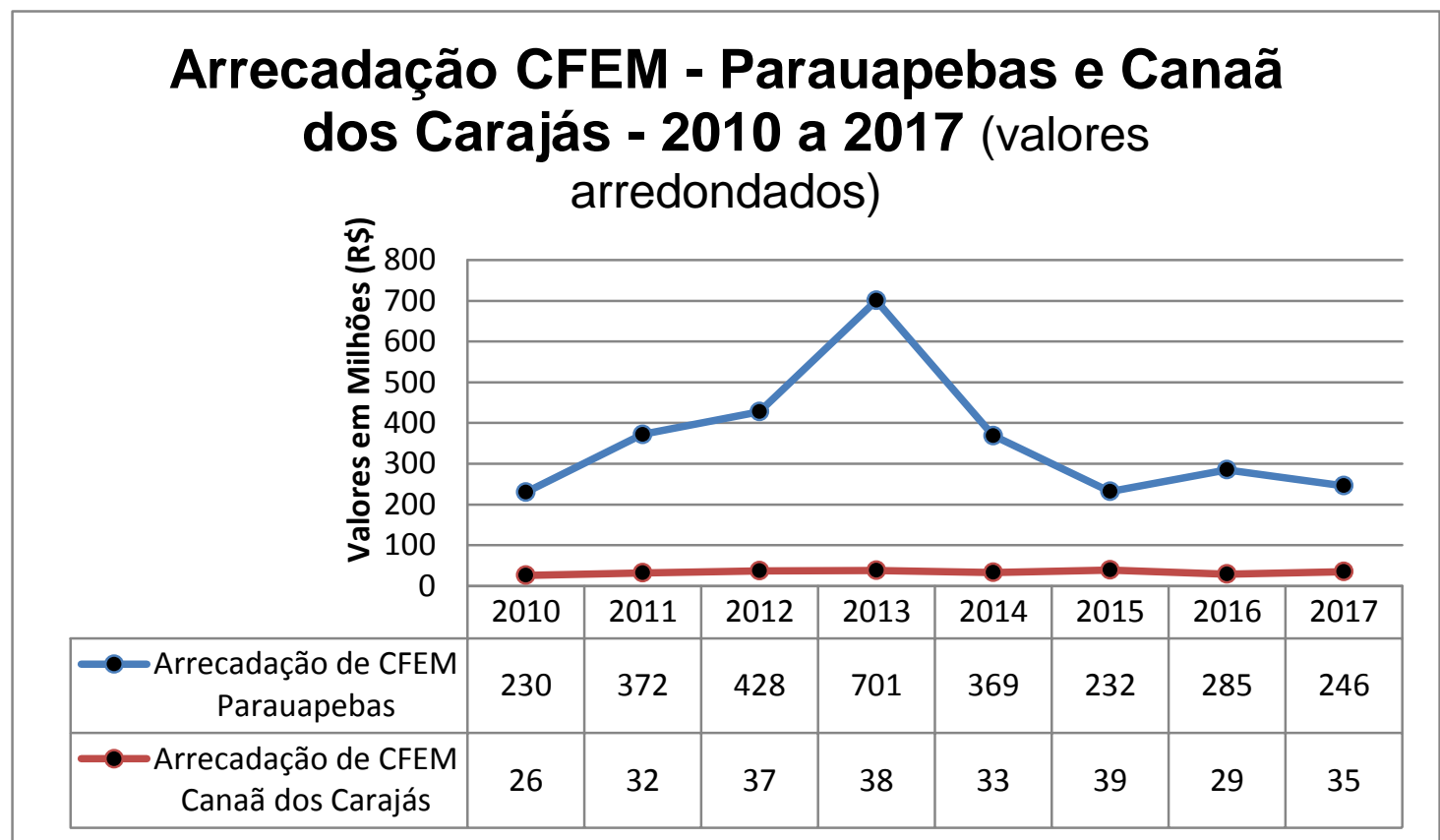

Gráfico 06 - Arrecadação CFEM em Parauapebas e Canaã dos Carajás 2010-2017 Fonte: DNPM (2017).

De acordo com o Gráfico 06, Parauapebas a arrecadação de CFEM tem oscilado, onde nos últimos 03 anos apresentou uma queda significativa em relação ao ano de 2013. Acredita-se que até o fechamento de 2017 a arrecadação aumente, tendo em vista, à última atualização do DNPM (julho de 2017) a arrecadação estava quase igual a todo volume arrecadado no ano de 2016.

Em relação ao município de Canaã dos Carajás a arrecadação tem se mantido constante, não ultrapassando o valor de 40 milhões de reais. Sua maior arrecadação foi no ano de 2013, chegando ao número de 38 milhões de reais.

Vale ressaltar que os produtos minerais encontrados em Parauapebas não são os mesmos produzidos em Canaã dos Carajás. Em Parauapebas a produção principal é o Minério de Ferro e em Canaã dos Carajás, até ao final do ano de 2016 o município produzia de forma expressiva o Minério de Cobre, tendo seu quadro alterado a partir de 2017, devido à startup em dezembro de 2016 da S11D - Eliezer Batista, o maior Complexo Minerador de Minério de Ferro do mundo da empresa Vale.

De acordo com o DNPM, em 2016 a produção de Minério de Cobre em Canaã dos Carajás (respeitando o mesmo período de janeiro a julho), foi de um pouco mais de 17 milhões de reais. Em 2017 esse número subiu para quase 19 milhões de reais, um incremento de quase dois milhões de reais em arrecadação de CFEM do ano anterior.

Lembrando que de acordo com o DNPM a distribuição da arrecadação da CFEM deve ser realizada entre Municípios, Estados e União, e é creditada de forma automática, 
| Gláucia Rodrigues Nascimento Medeiros | Marcus Vinicius Batella Medeiros |Luana Faria Medeiros | conforme apresentado anteriormente. A CFEM possui sua utilização destinada a projetos diretos ou indiretos revertidos para a comunidade local, sendo direcionada a aplicação, em melhorias da infraestrutura, da qualidade ambiental, da saúde e da educação. O DNPM ainda informa que é terminantemente proibida a utilização da CFEM para o pagamento de dívidas ou investimento no quadro permanente de pessoal da União, dos Estados, Distrito Federal e dos Municípios, sancionado através do Decreto no 01 de 11 de dezembro de1991.

Para ilustrar a importância que o município possui para a economia do estado do Pará, e o seu desempenho influencia automaticamente as receitas estaduais em arrecadação de CFEM em comparação com o município de Canaã dos Carajás, o Gráfico 07 apresenta o comparativo entre a arrecadação de CFEM do Estado do Pará e dos municípios de Parauapebas e Canaã dos Carajás.

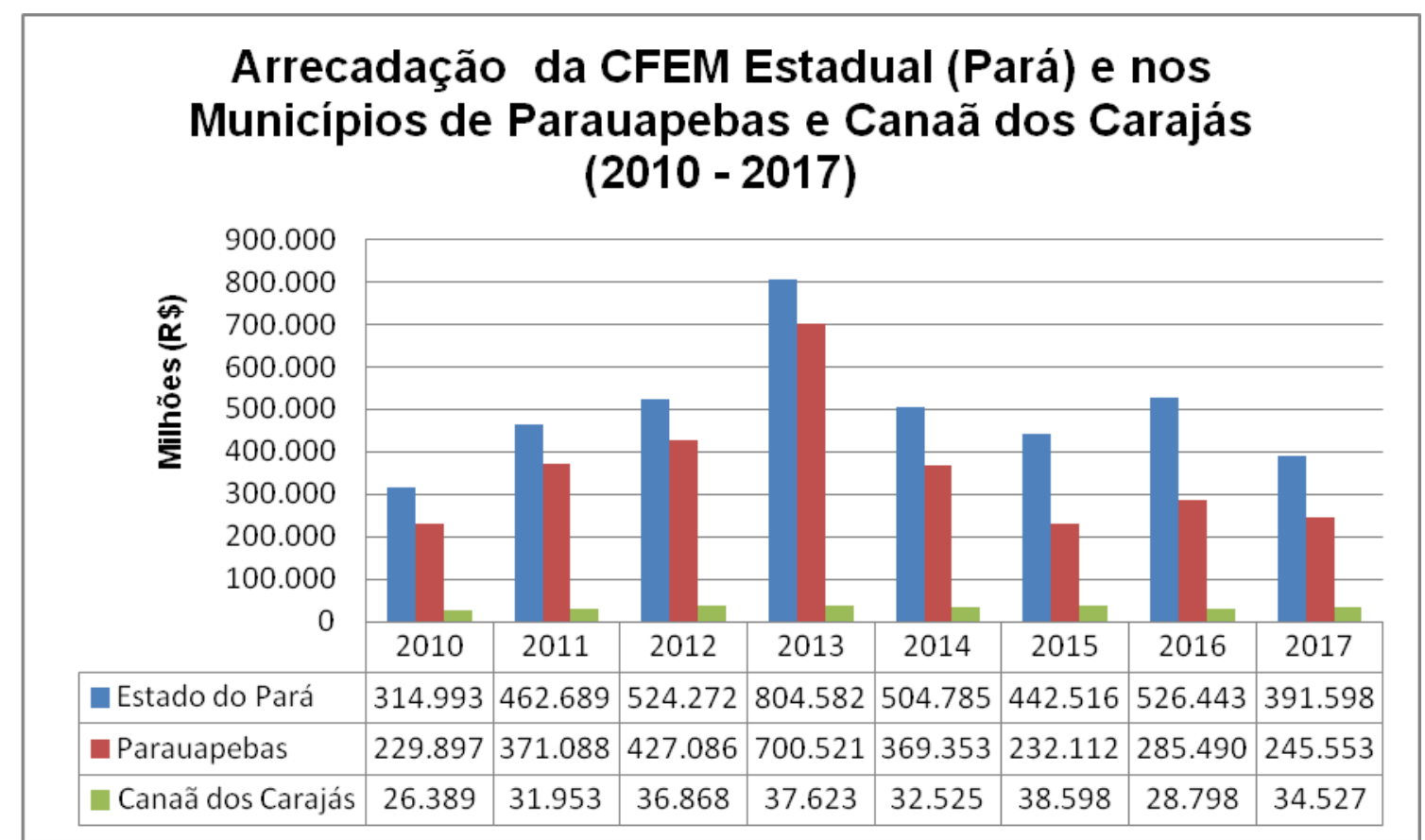

Gráfico 07 - CFEM Estadual e nos Municípios de Parauapebas e Canaã dos Carajás (2010 - 2017) Fonte: DNPM (2017).

De acordo com o Gráfico 07, o volume em arrecadação de CFEM do Estado do Pará está diretamente ligado à arrecadação do município de Parauapebas, tendo seu ápice em 2013. Para ilustrarmos a distância de volume de arrecadação entre os municípios de Parauapebas e Canaã dos Carajás, Canaã durante o todo o período não influenciou significativamente a receita estadual, quadro que provavelmente será alterado a partir de 2018, tendo em vista a empresa Vale começar a exportar o minério de ferro advindo da S11D. 
Dossiê: Impactos e repercussões territoriais de empreendimentos na Pan-Amazônia | Gestão do território: análise econômica da mineração nos municípios da Amazônia Oriental paraense (2010 a 2017)|

| Gláucia Rodrigues Nascimento Medeiros | Marcus Vinicius Batella Medeiros |Luana Faria Medeiros |

Ainda sobre o gráfico anterior, Parauapebas durante todo o período pesquisado se apresentou como o mais importante e expressivo na arrecadação de CFEM, conforme Gráfico 08:

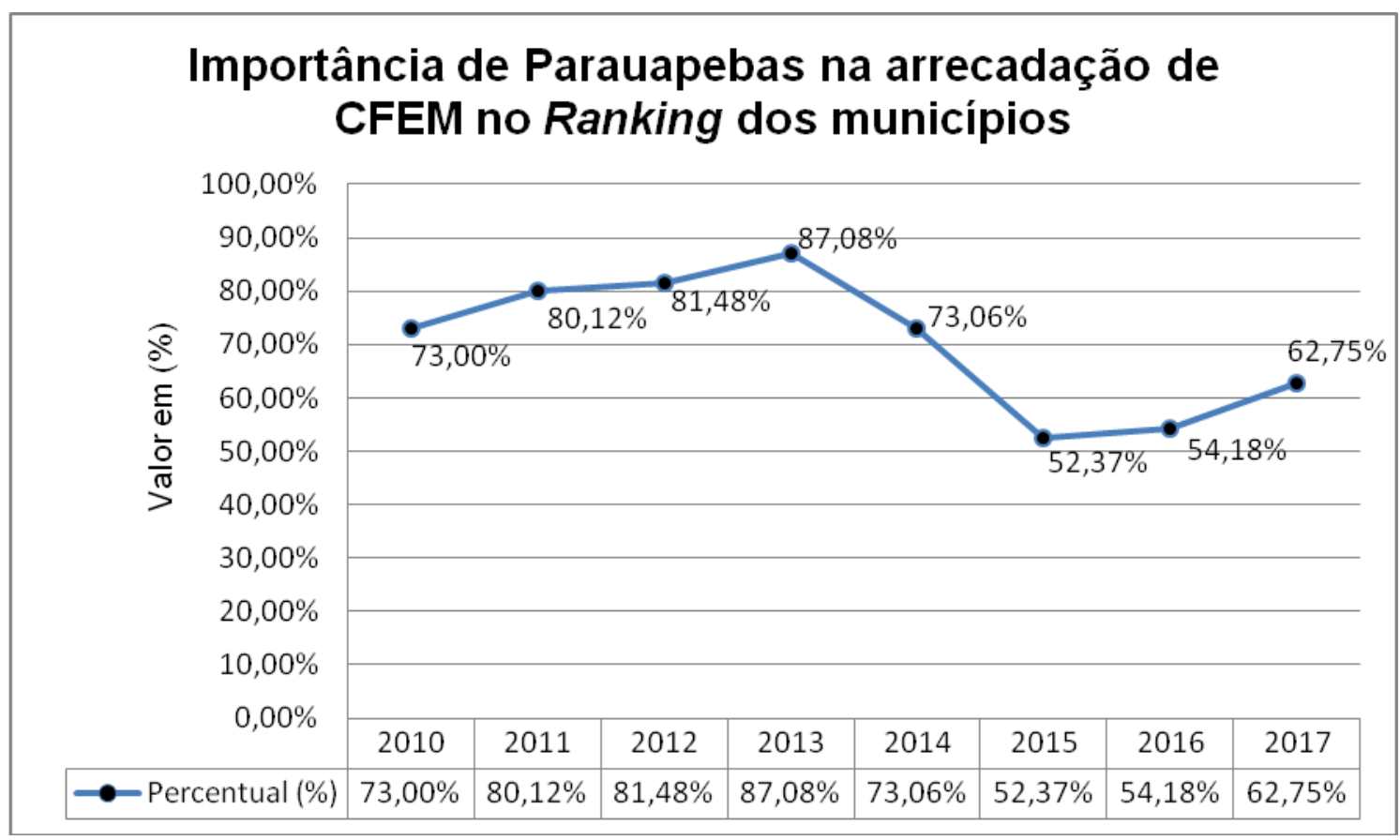

Gráfico 08 - A Importância de Parauapebas na arrecadação de CFEM no Ranking dos municípios Fonte: DNPM (2017).

No Gráfico 08, o município de Parauapebas representou durante todo o período pesquisado mais da metade de toda a arrecadação de CFEM do estado do Pará, chegando a representar em 2013 quase 90\% de todo volume arrecadado dos mais de 50 municípios paraense. Em 2015 esse volume despencou, caindo para 73\%, mesmo assim se manteve acima dos $50 \%$.

\section{CONSIDERAÇÕES FINAIS}

O presente artigo ao longo de toda pesquisa buscou apresentar a importância do Pará na economia nacional, quando o assunto se refere a royalties da mineração.

Sua importância vai além do potencial econômico, pois o Pará possui um dos territórios mais completos e complexos do planeta, se apresentando ao mundo como um dos maiores potenciais energéticos e composto por uma vasta riqueza natural em biodiversidade.

Além dos minérios mais desejados por toda potencia mundial, o estado possui em seu território bens com um alto valor agregado, fazendo parecer que o Artigo 20 da 
Dossiê: Impactos e repercussões territoriais de empreendimentos na Pan-Amazônia | Gestão do território: análise econômica da mineração nos municípios da Amazônia Oriental paraense (2010 a 2017)|

| Gláucia Rodrigues Nascimento Medeiros | Marcus Vinicius Batella Medeiros |Luana Faria Medeiros | Constituição Federal foi baseado em seu solo. Além do potencial mineral, o estado do Pará possui terras devolutas, rios, mar territorial, terrenos de marinha, potenciais de energia hidráulica, cavidades naturais subterrâneas e sítios arqueológicos, terras tradicionalmente ocupadas pelos índios, ou seja, possui praticamente todos os recursos naturais estratégicos para alavancar o desenvolvimento de gerações.

Embora o estado do Pará conte com todo esse potencial, os Estados e Municípios paraenses não possuem autonomia e tão pouco efetiva participação no poder decisório quanto à tomada de decisão geradora de desordenamentos territoriais, e imprevisibilidades relacionadas às despesas públicas municipais decorrentes da implantação de um grande projeto, que ao invés de promoverem o desenvolvimento local, quando não bem discutidas e analisadas em todas as esferas, mantendo uma contínua participação dos Stakeholders, poderá causar um efeito reverso, que além de comprometer o meio ambiente, as relações entre os entes federados, insatisfação da sociedade impactada, principalmente quando surge uma catástrofe natural decorrente de uma tomada de decisão errada, destroem as relações harmônicas em municípios pacatos, trazendo também fenômenos, relacionados ao êxodo rural, aumento no fluxo migratório para algumas regiões, consequentemente aumento nos índices de violência, incapacidade municipal para arcar com todas as despesas, entre outras problemáticas.

As questões sociais e ambientais não foram tratadas nesta pesquisa de forma intencional, pois se fazia necessário uma leitura panorâmica sobre quais possibilidades econômicas a mineração proporciona aos estados e municípios mineradores em focar seus investimentos aos fatores que a própria legislação prevê como sendo prioritárias para o desenvolvimento regional e melhor gestão territorial que é a infraestrutura, saúde, educação e meio ambiente. Pois se entende que a partir do direcionamento da CFEM para as devidas áreas é que se poderá pensar em políticas públicas mais eficientes e eficazes, não somente para a boa gestão territorial, mas principalmente para o aumento da qualidade de vida e bem-estar social.

Não se pode esquecer que os municípios mineradores possuem além de CFEM todos os outros investimentos do Governo Federal, direcionados tanto para a saúde, quanto para a educação, sem contar com os investimentos voltados à infraestrutura e meio ambiente, e mesmo assim os municípios não conseguem melhorar de forma significativa os indicadores mínimos avaliativos de qualidade.

Sendo assim, tornam-se essencial e imprescindível que os geógrafos de todas as regiões do país, busquem desempenhar papéis de fiscalizadores da coisa pública, através de 
Dossiê: Impactos e repercussões territoriais de empreendimentos na Pan-Amazônia | Gestão do território: análise econômica da mineração nos municípios da Amazônia Oriental paraense (2010 a 2017)|

| Gláucia Rodrigues Nascimento Medeiros | Marcus Vinicius Batella Medeiros |Luana Faria Medeiros | pesquisas, criando também instrumentos e indicadores mais personalizados e voltados às necessidades territoriais, utilizando também a interdisciplinaridade e multidisciplinaridade, a fim de se aproximar ao máximo do lócus de pesquisa, buscando fazer sempre uma análise sistêmica.

Vale ressaltar que o artigo não buscou realizar uma crítica negativa acerca do IBGE, e sim avaliar a eficiência dos indicadores em territórios com mineração, devido à necessidade de se identificar continuamente os fatores desencadeadores de conflitos, onde somente os dados do IBGE se tornam impossível uma análise qualitativa, devido ao lapso temporal.

Devido à natureza da mineração, ser uma exploração em um recurso não renovável, onde os efeitos negativos e a má qualidade nas tomadas de decisões públicas tanto do Poder Executivo, Legislativo e no Judiciário, onde podendo incluir as três esferas: Poder Federal, Estadual e Municipal, comprometerá tanto os municípios já impactados com a implantação de um grande projeto, em longo prazo, podendo acarretar em danos irreversíveis ao meio ambiente, às populações locais, tanto as urbanas quanto as rurais e tradicionais. A biodiversidade é a maior impactada em relação aos outros, pois é massacrada diariamente, afetando do local ao global, justificando uma contínua reflexão sobre qual a influência que a CFEM possui no investimento dos Estados e Municípios, considerando também o Federal, tendo em vista os valores arrecadados ao longo do ciclo dos grandes projetos aparentemente não têm agregado valores qualitativos aos territórios impactados, gerando gradativamente mais confrontos e conflitos, constantemente apresentados em noticiários, principalmente no entorno dos grandes projetos.

\section{REFERÊNCIAS}

ALTVATER, Elmar. O preço da riqueza: pilhagem ambiental e a nova (des) ordem mundial. São Paulo: Ed. UNESP, 1995.

ANDRADE, Regis de Castro. Processo de governo no município e no estado: uma análise a partir de São Paulo: EdUSP, 1998.

BRASIL. Constituição Federal de $1988 . \quad$ Disponível em: $<$ http://www.planalto.gov.br/ccivil 03/constituicao/constituição.htm>. Acesso em: 20 ago. 2017.

BRASIL, M. M. A. Ministério do Meio Ambiente. Responsabilidade Socioambiental, Agenda 21. Brasília: MMA/SBF, 2005. Disponível em: $<$ http://www.mma.gov.br/responsabilidade-socioambiental/agenda-21/documentos $>$. Acesso em: 23 ago. 2017. 
| Gláucia Rodrigues Nascimento Medeiros | Marcus Vinicius Batella Medeiros |Luana Faria Medeiros | CARLOS, Ana Fani Alessandri; SOUZA, Marcelo Lopes de; SPOSITO, Maria Encarnação Beltrão. A produção do espaço urbano: agentes e processos, escalas e desafios. São Paulo: Ed. Contexto, 2011.

CNM - Confederação Nacional de Municípios. Estudos Técnicos. Brasília: CNM, 2012. Disponível em: <http://www.cnm.org.br/cms/biblioteca/ET\%20Vol\%205\%20\%2014.\%20Entenda $\% 20 \mathrm{a} \% 20$ CFEM.pdf $>$. Acesso em: 22 ago. 2017.

CORRÊA, Roberto L. Algumas reflexões sobre a gestão do território. In: ENCUENTRO DE GEÓGRAFOS DE AMÉRICA LATINA, 2., 1989, Montevideo, 1989. Anais... Geografia, Poder y Planificación. Montevideo: EGAL, 1989. Disponível em: <http://www.observatoriogeograficoamericalatina.org.mx/egal2/Geografiasocioeconomic a/Ordenamientoterritorial/03.pdf > . Acesso em: 20 ago. 2017.

DNPM - DEPARTAMENTO NACIONAL DE PRODUÇÃO MINERAL. Relatório CFEM maiores arrecadadores. Brasília: DNPM, 2016. Disponível em: $<$ https://sistemas.dnpm.gov.br/arrecadacao/extra/Relatorios/cfem/maiores arrecadador es.aspx >. Acesso em: 22 ago. 2017.

IBGE - Instituto Brasileiro de Geografia e Estatística, 2010/2016. PIB - valores correntes. Disponível em: <http://brasilemsintese.ibge.gov.br/contas-nacionais/pibvalores-correntes.html>. Acesso em: 21 ago. 2017.

INMETRO. Compreendendo a Responsabilidade Social. Disponível em: $<$ http://www.inmetro.gov.br/qualidade/responsabilidade social/cartilha compreendendo a responsabilidade social.pdf >. Acesso em: 15 ago. 2017.

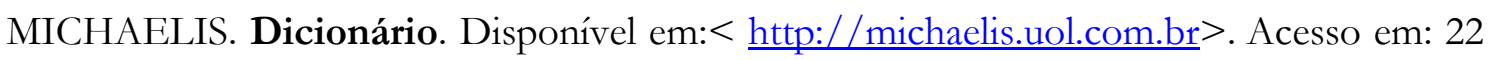
ago. 2017.

MUNICIPIOS. Perfil. Meu município. Disponível em: $<$ https://meumunicipio.org.br/perfil-municipio/1502152-Canaa-dos-Carajas-PA $>$. Acesso em: 23 ago. 2017.

PLANALTO, Palácio do. Lei número 8.876, de 02 de maio de 1994. Brasília: Presidência da República, 2007. Disponível em: < http://www.planalto.gov.br/ccivil 03/leis/L8876.htm>. Acesso em: 22 ago. 2017.

Ato 2015-2018. Presidência da República. Brasília, 2017. Disponível em: <http://www.planalto.gov.br/CCIVIL 03/Ato2015-2018/2017/Mpv/mpv791.htm>. Acesso em: 25 ago. 2017.

Lei 7990. Presidência da República. Brasília, 2007. Disponível em: <http://www.planalto.gov.br/ccivil 03/leis/L7990.htm> . Acesso em: 25 ago. 2017.

RAFFESTIN, Claude. Por uma geografia do poder. Rio de Janeiro: Ática, 1993.

RIBEIRO, Hidelberto de S. Políticas territoriais e colonização numa área da Amazônia oriental. Dissertação (Mestrado em Geografia Humana) - Departamento de Geografia, Faculdade de Filosofia, Letras e Ciências Humanas, Universidade de São Paulo, 1993. 
Dossiê: Impactos e repercussões territoriais de empreendimentos na Pan-Amazônia | Gestão do território: análise econômica da mineração nos municípios da Amazônia Oriental paraense (2010 a 2017)|

| Gláucia Rodrigues Nascimento Medeiros | Marcus Vinicius Batella Medeiros |Luana Faria Medeiros |

RODRIK, Dani. A Globalização foi longe demais?. São Paulo: Ed. Unesp, 2011.

SEAD - Secretaria de Administração. Governo do Pará lança oficialmente o programa "Pará 2030", de 30 de junho de 2016. Disponível em: $<$ http://www.sead.pa.gov.br/noticia/governo-do-par\%C3\%A1-lan $\% \mathrm{C} 3 \% \mathrm{~A} 7 \mathrm{a}-$ oficialmente-o-programa- $\% \mathrm{E} 2 \% 80 \% 9 \mathrm{Cpar} \% \mathrm{C} 3 \% \mathrm{~A} 1-2030 \% \mathrm{E} 2 \% 80 \% 9 \mathrm{D}>$. Acesso em: 27 ago. 2017.

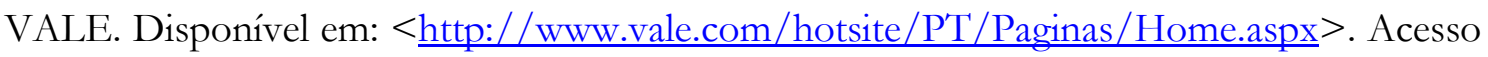
em: 24 ago. 2017

VILLELA, Marcelo. Governo extingue Reserva Nacional de Cobre e Associados para atrair investimentos em mineração. Brasil InfoMine, Nova Lima, ago. 2017. Disponível em: $\quad<$ http://noticiasmineracao.mining.com/2017/08/23/governo-extingue-reservanacional-de-cobre-e-associados-para-atrair-investimentos-em-mineracao/>. Acesso em: 28 ago. 2017. 